\title{
Arbor
}

\section{El Español como Lengua de Comunicación Científica}

\author{
Ángel Martín Municio
}

Arbor CLXXIX, 706 (Octubre 2004), 525-540 pp.

No tiene demasiada importancia si las primeras señales de una incipiente comunicación científica fueron los elementales algoritmos de las tablillas de arcilla en el periodo paleobabilónico, o los cálculos de volúmenes en los papiros egipcios del segundo milenio antes de nuestra era, o el sistema sexagesimal mesopotámico. Da igual porque la comunicación matemática nació cuando, cientos de miles de años antes, las conexiones sinápticas del cerebro en evolución permitieron al hombre contar, en coincidencia con el origen del lenguaje y en coincidencia con el origen de su propia naturaleza; para, luego, en su interacción con el pensamiento, comenzar el razonamiento abstracto. Y no será en vano que filósofos, lingüistas y antropólogos, coinciden en reconocer que sin el concurso de los signos seríamos incapaces de reconocer las ideas. El pensamiento en sí mismo sería como una nebulosa donde nada está necesariamente delimitado, y donde nada sería distinto antes de la aparición de la lengua. De aquí que el pensamiento sea imposible sin lenguaje; y más aún, como aseguró en el siglo XVIII el gran naturalista Buffon, el hombre habla debido a que tiene razón. Y es así que todo hombre piensa en su lengua, y ella se identifica con sus imaginaciones y sentimientos.

De esta manera, el lenguaje sirvió siempre para expresar las preocupaciones del pensamiento acerca del origen y la naturaleza del hombre y del universo. Y expresión de estas preocupaciones habrían de ser las creaciones literarias mítico-religiosas en todas las lenguas; las que darían paso a la exaltación artística de los mitos y, a su lado, al razonamiento filosófico y al razonamiento matemático. 


\section{Ángel Martín Municio}

Y no deja de ser impresionante que hoy, al cabo de tantos años, la moderna imagen funcional del cerebro, que, a no dudarlo, ha nacido a expensas de la matemática moderna, sea capaz de mostrarnos una localización cerebral del ejercicio matemático, diferente de la localización responsable del lenguaje. Si esta habilidad matemática, consustancial por otro lado al ejercicio de la ciencia, fue, pues, independiente a la vez que pareja al lenguaje, competencias ambas intrínsecas del hombre, no tendrá nada de extraño que la marcha de ambos haya caminado en paralelo. Y que una de las particularidades más significativas de la expresión del pensamiento del hombre, con sus altibajos y sus renovaciones, haya sido siempre la preocupación científica por su propia naturaleza y la de su presencia en el universo.

No dejará de tener que ver con esta relación el que, efectivamente, la matemática griega naciera en perfecta unidad con la filosofía; y el que, de su identificación naciera el método axiomático-deductivo, aún en vigor para la correcta demostración de las verdades establecidas por los teoremas. Y, así, Pitágoras, en el siglo VI antes de Cristo, a la vez que impuso la disciplina de la demostración, viajó sus teorías por Babilonia y Egipto, y, en Crotona enseñó en el Senado a las mujeres, a los jóvenes y a los niños en una labor de formación intelectual y moral de la sociedad de la época. Insistía Pitágoras en estas instrucciones acerca de la necesidad de acomodar el comportamiento humano a los cánones de la armonía y la exactitud mostrados por la precisión de los descubrimientos del universo y de la naturaleza misma de las cosas. Pitágoras y sus seguidores trataron de descubrir las propiedades inmutables de los objetos matemáticos, prescindiendo de sus inmediatas cualidades utilitarias tan propias de la ciencia oriental. Y, sin duda, fue este el motivo por el que la nueva matemática griega se sintió objeto de estudio singular por la filosofía, en busca de lo permanente y eterno.

De entonces acá, las obras de Arquímedes, Euclides y Apolonio de Perga, y su sistematización, tuvieron vigencia hasta el Renacimiento. La fama de Arquímedes, precursor en la Antigüedad de los métodos infinitesimales, se ha debido tanto a su obra como a su vida, embellecida y deformada por las anécdotas de la imaginación popular, cuyo símbolo fue su muerte, atravesado por la espada de un soldado romano mientras, negándose a dejar inconclusas sus investigaciones, contemplaba absorto sus figuras geométricas. Y los "Elementos", de Euclides, en sus trece libros, y con la Biblia las dos obras que más ediciones han conocido y entre las de mayor influencia cultural en la historia de la civilización, recopilan ordenadamente definiciones, postulados y axiomas y proposiciones, 


\section{El Español como Lengua de Comunicación Científica}

de tal forma que Rey Pastor pudo afirmar de ellos: "Si pretendieras agregar o quitar algo reconocerías de inmediato que te alejas de la ciencia y te acercas hacia el error y la ignorancian.

Tras todo ello, hubo de atravesarse la larga Edad Media en la que los diez siglos árabes y latinos ocuparon un lugar esencial en los orígenes de la ciencia europea. No en vano, las ciencias del cálculo -la aritmética, el álgebra y la trigonometría - las ciencias de lo concreto y lo práctico, deben quizá más a la ciencia oriental que a la griega; y en esas rutas hacia Europa de la matemática y la ciencia greco-oriental -de las que España fue, sin duda, la principal vía de paso- el papel del mundo árabe significó algo más que el de un simple intermediario y aparece representado principalmente por el álgebra de Al-Khwarizmi y la trigonometría esférica de Ibn al-Haytham, o Alhazen, autor de un tratado de Óptica que sirvió de guía de los conocimientos sobre la luz y la visión en el Oeste europeo medieval.

Precisamente, una de las interacciones entre el Oeste europeo y los centros peninsulares de la ciencia árabe, al finalizar el primer milenio, fue la que representó el tratado De Astrolabia, del obispo de Reims, Girberto d'Aurillac, pronto Papa Silvestre II. A la vez, el Canon de Medicina del médico y filósofo Ibn Sina, o Avicena, consolidó el conocimiento médico acumulado por griegos, romanos y árabes. La Óptica de Alhazen y el Canon de Avicena han servido tradicionalmente como piezas maestras para enmarcar el estado de la comunicación de la ciencia universal en la transición al segundo milenio.

Momento este, por otro lado, que supuso la trascendente iniciación del castellano, cuando, en el siglo X, el scriptorium de San Millán, centro neurálgico de su biblioteca, pudo participar en el porvenir de la lengua neonata con los Comentarios a los Salmos, la copia de la Ciudad de Dios de San Agustín, y, sobre todo, el famoso códice 46, diccionario enciclopédico de la época con el vocabulario, la cultura y el pensamiento medievales. Y, ante aquellos iniciales documentos, ante las innovaciones y las vacilaciones lingüísticas de hace un milenio, no tenemos sino que reconocer con Marañón los esfuerzos de los que nos precedieron en los siglos pasados, porque "los que heredan una gran riqueza no se dan cuenta de ella como los que han tenido que ganarla con su esfuerzo. Nosotros tenemos situación de privilegio por haber aprendido esta lengua clara de Castilla. Pero este privilegio lo tenemos que merecer cada día con nuestro esfuerzo y con nuestro amor. El tesoro de una lengua ilustre significa un servicio permanentemente alerta, un anhelo constante de perfección". 


\section{Ángel Martín Municio}

Lo han merecido, en efecto, todos los que, tras los balbuceos monacales, han ido pasando hasta nuestros días el testigo de la perfección y la belleza de la lengua, de un lado, y, de otro, los que en empresas militares, misioneras y colonizadoras, la aventaron por mares y continentes. Porque cinco siglos antes de que el castellano pasara a ser universalidad en Lope, y en Cervantes el arranque de los tiempos modernos en la historia del hombre; porque, también, mucho antes de que la lengua se hiciera norma en la gramática de Nebrija, poesía en Garcilaso, novela en El Lazarillo, comedia en La Celestina y perfección en Fray Luis; y porque, y aún antes de que la lengua se convirtiera en dejes de melancolía en las coplas de Jorge Manrique, y de que fuera picardía popular en los versos del Arcipreste, el castellano, a modo de romance, acompañó al Cid en sus correrías militares y, prácticamente a la vez, sirvió ya a Alfonso X el Sabio como lengua de la ciencia y de la técnica en El Saber de Astronomía y en El lapidario y como lengua enciclopédica de cultura, y del derecho y la ley en Las Partidas.

Mediado el siglo XIII, los grandes libros de la ciencia griega, los de la filosofía natural de Aristóteles y los de matemáticas -los Elementos de Euclides, el Almagesto de Ptolomeo, y algunos otros de Arquímedes y Apolonio- contaban con traducciones latinas para su estudio en las universidades del Oeste europeo. Y, entre 1240 y 1270, los dominicos Alberto Magno y Tomás de Aquino acomodaron la doctrina aristotélica al pensamiento cristiano. Esta indudable revolución del pensamiento religioso no fue acompañada en la misma medida por una revolución científica. De todas formas, el franciscano de Oxford Roger Bacon se había esforzado en independizar la rudimentaria ciencia física de la teología y la filosofía medievales; y el comienzo de la observación y la experimentación condujo en seguida a mejoras en la producción agrícola, un aumento del comercio y los medios de transporte y de todas las artes mecánicas. Bacon, en resumen, preparó el giro del espíritu europeo en la transición medieval a la Edad Moderna. Duns Escoto y Guillermo de Occam siguieron el ejemplo precursor de Roger Bacon y contribuyeron en gran medida a la independencia de la ciencia de sus lastres escolásticos; ayudaron a la pretensión de Bacon de una ciencia fundada exclusivamente en la experiencia inmediata y en la observación de la naturaleza, con lo que se habría de iniciar el despliegue de la poderosa ciencia natural de Occidente. Y, así, entre los acontecimientos más ricos en consecuencias de esta época de transición se cuentan tres grandes inventos: la brújula, las pólvora y la imprenta, que trastocaron el orden medieval y transformaron la visión social, política y cultural de Europa. 


\section{El Español como Lengua de Comunicación Científica}

Ocurría, además, que el entorno medieval de la ciencia venía siendo terriblemente limitado, y pocas alegrías científicas permitía; de un lado por los vaivenes económicos en los que tomó parte la economía feudal; y, de otro, debido a la vinculación casi exclusiva de la ciencia al alumbramiento de las verdades teológicas y de una sabiduría global al servicio de Dios. Tampoco esta situación facilitó los avances que la aún alquimia permitía. La iglesia, los monarcas y la literatura misma lanzaron sus sátiras y sus condenas sobre los alquimistas. La Divina Comedia les tortura en las regiones más profundas del infierno y son ridiculizados en los Cuentos de Canterbury. Enrique IV de Inglaterra y Carlos V de Francia promulgaron edictos contra ellos, persiguieron sus prácticas e incautaron los instrumentos de sus operaciones. En 1317, el Papa Juan XXII decretó que la alquimia fuese prohibida y castigados los que la practicasen y considerados criminales si no pudieran satisfacer las penas económicas impuestas; los clérigos perderían todos sus beneficios y serían inhabilitados para percibir cualquier otro".

Si la transición al siglo XVI supuso, con Cristóbal Colon y Vasco de Gama, el descubrimiento de nuevos mundos sobre la Tierra; en la transición al siglo XVII, Galileo dirigió su telescopio a los cielos y allí descubrió también nuevos mundos: que Júpiter tenía lunas, que Venus tenía fases, el Sol manchas y la Luna montañas. De esta manera, si Europa tuvo que empezar a compartir con América su presencia de todo tipo en la Tierra, el cosmos geocéntrico hubo de dejar paso a la imagen heliocéntrica del universo, y la humanidad se vio desplazada desde una posición central predominante, en el medio de todo, al lugar periférico de un planeta menor. Y no cabe la menor duda de que los cambios sociales y políticos medievales bajo la influencia de los inventos de la técnica, los descubrimientos y descripciones de los nuevos mundos, y los desamarres escolásticos, experimentaron un cierto tipo de coalescencia bajo la cual hubo de propiciarse el nacimiento de la ciencia moderna. Los Principia de Newton, en 1687, como un modelo para la descripción exacta de la naturaleza, significaron el comienzo de la ley y el orden en el mundo físico, y las posibilidades de alcanzar a la descripción del cuerpo humano y de la mente.

Entre tanto, el castellano se había hecho universal con las Crónicas de Indias de los protagonistas descubridores -Colón, Cortés, Díaz del Castillo, Valdivia, Núñez Cabeza de Vaca, Jiménez de Quesada y Cieza de León-. Y si la lengua tuvo a la vez en el Inca Garcilaso un espléndido ejemplo de transducción lingüística y cultural, y el origen de la dimensión de la literatura americana, fueron también el Descubrimiento, sus 
expediciones, viajes y navegaciones, razones de varias de las aventuras españolas del conocimiento en aquellos siglos. Era, es bien sabido, la época de los viajes de Magallanes y Elcano, de la estancia de Pizarro en Perú y de Cortés en Méjico, y de la apertura de la ruta de las Indias por Vasco de Gama. Lo que forzosamente había de repercutir en el interés singular por las aplicaciones náuticas y cartográficas de la ciencia física y matemática. Y a la vez, indudable por otro lado, que el ambiente de la Corte española favorecía el fomento de las aplicaciones pragmáticas de las matemáticas: la cosmografía, la cartografía, las mediciones geodésicas, la astrología, el arte de navegar, las técnicas de arquitectura y construcción, y la ingeniería militar.

A la sagacidad de Felipe II no pudieron hurtársele ni la decadencia de nuestra matemática, ni que la causa de los errores de nuestras cartas náuticas fuera la falta de conocimientos científicos. Por ello, y como reacción a los nuevos descubrimientos y garantía del éxito de los exploradores y de la resolución de problemas prácticos, Felipe II firmó en Lisboa, el 25 de diciembre de 1582, las cédulas fundacionales de la Academia Real Matemática. Acerca de ella, en la dedicatoria a Felipe II que Raimundo Lulio hizo de su Arbor scientiae, se puede leer: ".....mayormente aviendo V.M. en sus felicissimos dias hecho una merced tan señalada en establecer en esta su Corte una Academia donde se leen todas las Mathematicas y Philosophia, poniendo para ello maestros tan eminentes y de tanta erudición y experiencia. Púselo en nuestra lengua Castellana por ser la voluntad de V. Magestad que en V. Academia se lean todas las sciencias en esta lengua, para que tanto bien sea a todos más facilmente aprehendido y comunicado".

En esta iniciativa hubieron de pesar varios motivos: de un lado, el ambiente creado en la Corte por la convivencia de ingenieros civiles y militares, cosmógrafos, arquitectos y artilleros; de otro, la necesidad de buscar aplicaciones prácticas a las matemáticas que se hicieran patentes en las mediciones geodésicas, la cartografía y el arte de navegar; y, además, a no dudarlo, el ambiente luliano como movimiento renovador intelectual. La institución de la Academia tuvo, de otro lado, una doble finalidad: en primer lugar, la de coordinar y relacionar a científicos y técnicos con la clara orientación práctica de todas las disciplinas soportadas por las matemáticas; a lo que añadir la importancia del esfuerzo científico cooperativo y la diseminación social del conocimiento científico.

Entre los profesores de la Academia Matemática figuraron los portugueses Juan Bautista Labaña y Luis Georgio, y el italiano Julián Ferru- 


\section{El Español como Lengua de Comunicación Científica}

fino. Labaña, sin haber cumplido los 30 años, fue reclamado por el Rey de quien recibiría el título de Cosmógrafo mayor. Luis Georgio tuvo un papel protagonista en los trabajos de demarcación de los límites de las tierras conquistadas en las Indias occidentales y en Oriente. Ferrufino, a la muerte del primer director Herrera y de Felipe II, era el único profesor encargado de la totalidad de los asuntos de la Academia, y del que se dijo que leyó los cuatro primeros libros de Euclides y la materia de la esfera con tanta claridad y demostración que lo entendieron los más rudos. Y no deja de ser curiosa la mención de estos famosos profesores por parte de algunos de sus alumnos que no lo fueron menos. Así es el caso de la Epístola de Belardo a Amarilis, en la que Lope habla de sus estudios: primeras letras, artes, Raimundo Lulio, matemáticas....; y, con más detalle, en el acto V de La Dorotea, el autor, por boca de uno de sus personajes, afirma: "Esto estudié en mi tierna edad del doctísimo portugués Juan Bautista Labaña, y solo tal vez juzgo por curiosidad, y no de otra suerte, algún nacimiento; pero no responde a las interrogaciones por ningún caso. El hombre no se hizo por las estrellas, ni el libre albedrio les puede estar sujeto...". Y en la Jerusalén conquistada, una marca original anota "Juan Baptista Lauaña, Mathematico insigne", y, a su lado, los versos: "Maestro mío, si la Etherea mides / o Elementar región, o por la historia / real de España despreciaste a Euclides, / no dejes en sus líneas mi memorian.

Si la Academia Matemática cumplió en el siglo XVI una misión que bien tuvo que ver con el conocimiento científico y técnico imprescindible a la materialidad de la empresa descubridora, la colonización y, en particular, las grandes expediciones científicas, representaron una impresionante aventura del conocimiento. Sus misiones científicas, concretadas las más de las veces a los campos reducidos de la botánica, la minería y la metalurgia, sacaron a relucir nombres ilustres -Alonso Barba, José Celestino Mutis, los hermanos Fausto y Juan José Elhuyar, entre otrosque pusieron en marcha durante muchos años numerosas iniciativas sociales, científicas y del pensamiento, universidades incluidas, bajo el amparo de la lengua. Iniciativas, experiencias y entusiasmo sin límites de las gentes de la ciencia, que afianzaron la personalidad cultural de los reinos americanos. Y fue bajo este ambiente cuando los españoles han realizado una de sus mejores aportaciones a la historia de la química; porque ha sido esta época la única de la historia en la que nombres españoles se inscribieron en la más famosa, universal y permanente de las cartas de la ciencia: el sistema periódico de los elementos. Figuran en él tres elementos químicos -el wolframio, el vanadio y el platino- en la his- 
toria de cuyos descubrimientos aparecen, respectivamente, los hermanos Elhuyar, el alcalaíno Andres Manuel del Río y el famoso marino Antonio de Ulloa. Estoy seguro de que no existe mejor escaparate externo, ni esquema que más veces se haya reproducido en infinidad de libros de todas las lenguas, que el simbolismo universal de la carta periódica de los elementos. Y en esta formidable comunicación de la ciencia, en esta historia, ni antes ni después de la Ilustración ha habido otros nombres españoles descubridores de elementos químicos; época en la que, como en ninguna otra, se acercó a Europa la naciente ciencia española.

Ocurría, además, y sigue ocurriendo, que las regiones periféricas, y este rincón americano lo era, tienen un singular metabolismo cultural. Ocurría y ocurre que la distancia de los centros neurálgicos de renovación cultural hace que sus propios productos sean recibidos con el retraso suficiente para que se ofrezcan distintos y, con apariencia de estatismo se conserven más tardíamente. Y es allí mismo -asegura Maraval-, en esas regiones periféricas, en las que lo que se recibe de dentro con retraso se combina con lo que viene de fuera como novedad adelantada, son el lugar en que se produce de ese modo una primera síntesis de lo viejo y lo nuevo, de lo propio y lo ajeno, según un ritmo muy característico de retraso y anticipación. Conforme a estas ideas, fue Mutis con toda seguridad uno de los representantes periféricos más fieles a esa especie de mosaicismo cultural, a ese cambio de actitud mental, social y científica del hombre renacentista, cuando contempla la nueva relación del hombre consigo mismo y con el mundo, sus nuevas tierras, sus nuevos mares y su nueva naturaleza, la nueva dimensión de la soledad y la distancia. Porque renacentista fue la atención tan singularizada que Mutis prestó a la experiencia y a la producción de libros sobre plantas. Pero, a la vez, sintió Mutis la necesidad ilustrada de una nueva organización para responder a las apetencias del conocimiento racional, del dominio de la naturaleza y de las causas de las cosas. Y a pesar de que, desde su llegada a Nueva Granada, tuvo que esperar 23 años para conseguir la aprobación real de la expedición, Mutis dedicó a Carlos III, con el nombre de Borbonia Augusta, uno de los más bonitos ejemplares de la Flora de Bogotá. Fue testigo avisado del despertar del mundo cultural y político americano del siglo XIX, al que de tantas formas contribuyó, incluidas la educación y la formación de elites inquietas y dinámicas de sabios discípulos, y la creación de cátedras, programas y planes económicos, lingüísticos y culturales. Y al reseñar el encuentro de Mutis con Humboldt y Bonpland, bien merece la pena hacerlo con las mismas palabras que lo hizo el mejor historiador de la obra de Mutis, el Director de la Academia de la Historia de Colombia, Guiller- 


\section{El Español como Lengua de Comunicación Científica}

mo Hernández Alba: «Por dos meses comparten la mesa y el hogar del patriarca de los botánicos del Nuevo Mundo, que los desconcierta con su sabiduría increíble. Jamás soñaron los dos europeos encontrar en la lejana planicie bogotana una biblioteca especializada como en la misma Europa no llegaron a conocer. Ellos, tan difíciles de sorprender en cuestiones científicas, se vieron súbitamente en un paraíso sin sierpes engañosas, de que era soberano un anciano sacerdote, que hacía cuarenta años ilustraba las ciencias, en tales términos que sería pasmo de las edades".

La comunicación de la naturaleza recién descubierta, y sus maravillosas láminas y dibujos, estuvieron a tono con las descripciones naturalistas, exaltadoras de su belleza y originalidad. Sin embargo, ni las Instituciones de la Corona, ni los propios directores de las expediciones y proyectos, supieron sobrepasar el simple inventario de la naturaleza y emparejarse con la interacción multidisciplinar, esencial a la evolución del conocimiento, que ya estaba al uso en Europa y que, sobre todo, en Francia y Alemania había logrado utilizar las plantas para la determinación de las estructuras químicas de sus productos y sus aplicaciones farmacológicas.

Y hubo de comenzar el bautizo de la inmensa colección de productos naturales aislados de las plantas, contando con la gran suerte de la previa denominación sistemática botánica que se ha ajustado siempre a los más estrictos cánones clásicos. De esta manera, a lo largo del siglo XIX, hubo que nombrar la gran colección de sustancias químicas recién descubiertas; por ejemplo, de los bulbos de Colchicum autumnale se aisló y nombró la colchicina (Pelletier y Caventou, 1820); de las hojas de Nicotiana tabacum se aisló y nombró la nicotina (Posselt y Reimann, 1828); de las hojas de Erythroxylon coca se aisló y nombró la cocaína (Niemann, 1860); y la pilocarpina (Gerrard y Hardy, 1875) lo fue de las hojas de Pi. locarpus jaborandi.

Quizá sea conveniente resaltar en este momento que, con la entrada en el siglo XIX, se difuminó primero, y acabó en seguida colapsándose esa convergencia global de la ciencia española ilustrada con la ciencia europea. Sin entrar en las reconocidas razones de este fracaso, lo cierto es que durante el primer tercio del siglo XIX se frustraron los signos de continuidad científica a que España aspiró. Sucedió, y es también evidente, que cualquier intento de renovación, fuera educativa o de creación de instituciones, quedaba casi necesariamente rezagado y con perspectivas anticuadas; y la contribución de los científicos, en el mejor de los casos, era informativa y carente en general de la imprescindible aportación creadora. 
Y, en lógica consecuencia, muy poco es lo que España y su lengua contribuyeron en este siglo a esa fantástica misión de dar nombre a las cosas recién descubiertas. No estará de más, por otro lado, que recordemos lo que a la naciente ciencia europea le estaba reservado. Porque fue este siglo en el que, de manera completa, vivieron Bernard (1813-1878) y Pasteur (1822-1895) y descubrieron la etiología de las enfermedades y las primeras vacunaciones, y Darwin (1809-1882) publicó El origen de las especies. Fueron además los años de Koch (1843-1910) y del aislamiento de los bacilos del cólera y la tuberculosis; de Behring (1854-1917) y los sueros antibacterianos. Fueron los años de la genética de Mendel (1865), del descubrimiento de los cromosomas por Flemming (1875) y de los centros funcionales del cerebro por Charcot (1825-1893); de la síntesis de productos naturales, como el índigo, por Bayer (1879) y el gran desarrollo de la síntesis orgánica por Berthelot (1860); del descubrimiento de los rayos $\mathrm{X}$ por Röntgen (1895) y de la radiactividad por Becquerel (1896). Fueron los años del nacimiento de la termodinámica (1853), de la teoría de la valencia (1858), de la teoría de los campos electromagnéticos de Maxwell (1864), de la teoría cinética de los gases de Boltzmann (1877), de la teoría de los conjuntos de Cantor (1883), de la lógica matemática de Frege (1892) y de los números algebraicos de Hilbert (1897). A su lado, fueron también los años en los que se llevó a cabo la obtención industrial de la aspirina, del aluminio y del primer colorante artificial ; se abrió el primer pozo de petróleo, y se diseñaron el primer motor de explosión y el primer vehículo automóvil con motor de gasolina de cuatro tiempos; se tendió el primer cable trasatlántico y Bell inventó el teléfono; se fabricó el celuloide y la seda artificial; entró en funcionamiento la primera locomotora eléctrica de la Casa Siemens y el alumbrado eléctrico de Nueva York; y tuvo lugar la primera sesión pública de cine. Sin que, como manifestación de la gran cultura integrada, dejemos constancia de que en la misma época, en la década de los 50, se publicó Madame Bovary de Flaubert, en la década de los 60 Los miserables de Victor Hugo, en los 70 Una temporada en el infierno de Rimbaud, en los 80 Los hermanos Karamazov de Dostoievski, y en los 90 Cirano de Bergerac de Rostand. Y mucho menos de que, puertas adentro y en estas mismas décadas, pueda borrarse de la memoria la espléndida transición entresiglos de nuestra literatura con La Regenta de Clarín, Pepita Jiménez de Valera, Misericordia y Tristana de Galdós, y los Pazos de Ulloa de Pardo Bazán.

Esta visión crítica con que hoy contemplamos aquella época ya era bien patente dentro de ella. En este sentido se expresó don Cipriano Segundo Montesino, Duque de la Victoria, miembro de la Real Academia de 


\section{El Español como Lengua de Comunicación Científica}

Ciencias durante la segunda mitad completa del siglo XIX y Presidente de la Institución en las dos décadas finales del siglo (1882-1901), con motivo de su contestación al discurso de ingreso de don Práxedes Mateo Sagasta, en 1897: "....cuando nuestros Gobiernos se afanaban solícitos y generosos por restaurar y fomentar los estudios en España, sorprendiónos este tumultuoso y en todos sentidos agitadisimo siglo XIX, en cuyo primer tercio bastante hicimos con lograr salvarnos de la borrasca política y administrativa que en contra nuestra muy en sus albores se desató, y que en diversas ocasiones nos puso muy a punto de perecer, y amagó concluir más de una vez con la personalidad y la vida de la nación española». Y si, en efecto, bastante hicimos con salvarnos de la borrasca política, la ciencia, la técnica y la universidad, lograron descender hasta confundirse con el ruido de fondo social de las décadas centrales del siglo.

De todas maneras, este espíritu crítico de unos cuantos personajes de la ciencia fue capaz de sembrar una cierta inquietud por un despegue de ese ruido de fondo al que nuestra ciencia y nuestra técnica permanecían adheridos. Inquietud crítica puesta de manifiesto por don José Rodriguez Carracido, Rector de la Universidad Central, miembro de la Real Academia de Ciencias en los cuarenta años que comprendieron la época entresiglos y presidente de la Institución durante 1922-1928, en sus «Estudios histórico-críticos de la ciencia española». Entre sus numerosos comentarios, bien merece subrayarse uno por su permanente vigencia: "La idea de la inexcusable colaboración del medio social es la que conviene inculcar a todas las clases de nuestra patria para que presten su concurso al cultivo de la ciencia, y así cuando florezca y fructifique podrán llamarla suyar.

La historia nos prueba que nuestro último cuarto del siglo XIX se instauró en una múltiple vaguada; la de nuestro desarrollo científico, la de la institucionalización de la ciencia como actividad socioeconómica e, incluso, la de la consideración social de la ciencia. Y harto parece que de las inquietudes críticas de unos pocos y de las noticias y sucesos que llegaban de Europa, pudieran surgir individualidades e instituciones responsables de ese despegue de la pendiente a ras de suelo, con las que divisar, al menos, ya que no alcanzar, el imponente rastro europeo. Múltiple vaguada que alcanzó sus mínimos en las últimas décadas del XIX, y que, del costado de la modernidad, en los comienzos del nuevo siglo, ya tuvo atisbos de ilusión por la utilidad de la ciencia y el saber; y que, por tanto, habían de manifestarse en la aparición de los medios modernos de comunicación de la ciencia. Y así, la Sociedad Española de Física y Quími- 


\section{Ángel Martín Municio}

ca se constituyó en 1903, la Asociación Española para el Progreso de las Ciencias en 1908, y la Sociedad Matemática Española en 1911; cada una de las cuales tenía como más importante misión la publicación de la correspondiente revista con los trabajos originales de la incipiente investigación española; y, obligadamente, por supuesto, llevaban a cabo la conexión con las Asociaciones Internacionales y las Uniones Internacionales, elaboradoras de nomenclaturas y normas para la denominación de sustancias, fórmulas y fenómenos. Efectivamente, las asociaciones para el progreso de las ciencias fueron un curioso fenómeno asociativo, síntoma de la popularidad de la ciencia y del deseo de aumentar sus relaciones sociales, que se extendió por los grandes países europeos durante el siglo XIX. La alemana se fundó en 1822, la británica en 1831, la americana en 1848, y la francesa en 1872. Tampoco la universidad española, por otro lado, había logrado definir su modelo ni participar activamente en la creación científica. Como botón de muestra, las palabras de Ramón y Cajal en su discurso de ingreso en la Real Academia de Ciencias, exactamente en 1897: "Hay que transformar la Universidad, hasta hoy casi exclusivamente consagrada a la colación de títulos y a la enseñanza profesional, en un centro de impulsión intelectual, al modo de Alemania, donde la Universidad representa el órgano principal de producción filosófica, científica e industrial».

Si en la transición entresiglos hacia el XX se pudo vislumbrar una débil pero clara pendiente positiva en el avance de nuestra ciencia, $y$, por tanto, de nuestra comunicación científica, habrían de ser los mismos hombres del XIX -Cajal, Echegaray, Carracido, Torres Quevedo, entre los más sobresalientes- los que hubieron de regir las instituciones científicas y administrativas que, bajo la idea de ciencia experimental, maduraron en la primera década del XX: el Laboratorio de Mecánica aplicada (1906), el Laboratorio de Investigaciones físicas (1910) y la Junta para la Ampliación de Estudios e Investigaciones científicas (1907). Se trató, sin duda alguna, de una modesta incorporación de la ciencia española a las corrientes mundiales, con más entusiasmo y mejor intención que los resultados alcanzados. De esta ilusión fueron, sin duda, manifestación las palabras de Cabrera, en una recepción en la Academia de Ciencias con motivo de la visita de Einstein a España en 1923, bajo la presidencia del Rey Alfonso XIII, al asegurar: "...la España científica que hoy encontráis en embrión inicia el camino para llegar al lugar que tiene el inexcusable deber de ocuparm. Si, como es bien sabido, aquel embrión no pudo anidar en una matriz social que se resquebrajaría con consecuencia de la Guerra Civil, sí que pudo servir como siembra de la importancia del impacto 


\section{El Español como Lengua de Comunicación Científica}

intelectual y cultural de la ciencia. Comenzaron a tenerse presentes las consecuencias masivas de su utilidad y aplicación, y a considerar la ciencia como una actividad que contribuye al desarrollo del espíritu humano aunque su ejercicio no se haga con esta finalidad consciente. Bajo estas premisas, tomaba cuerpo la idea de valorar la idea humanista de la formación científica en sí misma, en tanto que los resultados experimentales trascienden, como ninguna otra faceta del conocimiento lo hace, los conceptos del universo y del hombre. Y, además, porque la propia actividad científica exige actitudes de las clásicamente consideradas como de corte humanístico, relativas, por ejemplo, a la historia, la economía, la política, la sociología e, incluso, la filología.

Consecuencia de todo ello -y del nacimiento en 1939 del Consejo Superior de Investigaciones Científicas y sus múltiples centros-, se sintió a mediados de siglo la necesidad de construir un Sistema Nacional de Ciencia y Tecnología, sobre la base de recomponer las funciones de asesoramiento, planificación, coordinación y gestión de las actividades de investigación científica y técnica. Y así surgieron: en 1958, la Comisión Asesora de Investigación Científica y Técnica (CAICYT); y en 1964, el Fondo Nacional para el Desarrollo de la Investigación Científica. Inaugurada en 1979 la primera legislatura constitucional, el artículo 44.2 de la Constitución asegura "que los poderes públicos promoverán la ciencia y la investigación científica y técnica en beneficio del interés general». En 1981, se creó la Comisión Delegada de Política Educativa, Cultural y Científica; en 1986, se aprobó la Ley de Fomento y Coordinación General de la Investigación Científica y Técnica, en cuyo $\operatorname{art}^{0} 6.1$ se establecía la obligatoriedad de remitir a las Cortes Generales el Plan Nacional de Investigación Científica y Desarrollo Tecnológico, y sus informes y revisiones anuales. Al iniciarse la legislatura de 2000, ha sido creado el Ministerio de Ciencia y Tecnología.

De esta manera, en el último cuarto del siglo XX, la ciencia española se ha visto sometida a una triple interacción. En primer lugar, la provocada por la perseverante acción encaminada a la mejora de la situación investigadora general $y$, particularmente, en algunos campos de la ciencia -la formación de científicos en el extranjero, la conexión con centros de Europa y Estados Unidos, la creación de reducidos grupos de excelencia, la presencia en Centros y Agencias internacionales de investigación científica y técnica, etc.- que si bien es cierto no ha podido conducir por sí sola a una situación de convergencia real con la ciencia europea, es innegable a la vez su contribución a la mejor disposición potencial para este logro. En segundo término, la indiscutible y notable mejora de la eco- 
nomía nacional, expresada a través de parámetros que como el PIB ha experimentado durante la segunda parte del siglo XX una elevación superior al 400 por ciento. Circunstancia que si, efectivamente, no debe prácticamente nada a la contribución de una tecnología propia subyacente, también es cierto, de un lado, que no logrará mantenerse a largo plazo sin la participación importante de ella, y, de otro, que esta mejora y esta presencia española en el Tratado de la Unión Europea (1991), y el cumplimiento de los criterios de convergencia económica, con la participación en el Instituto Monetario Europeo y en el Sistema Europeo de Bancos Centrales, han de facilitar ulteriores misiones de convergencia científica y tecnológica. Y, en tercer lugar, que la plena incorporación de España al Gobierno Económico de la Unión, en el seno de la unificación económica y monetaria, no podrá lograrse sin las adecuadas convergencias -de las actividades educativas y de $\mathrm{I}+\mathrm{D}$, de la adaptación a las nuevas tecnologías, de la liberalización de la competencia, etc.- y las oportunas reformas estructurales que exigirá el crecimiento sostenido de la producción.

Todo este conjunto de circunstancias han participado en la plena incorporación actual de nuestra comunicación científica a la cultura de la ciencia. Y a este respecto conviene destacar la existencia de un interés renovado por la filosofía de la naturaleza que se nutre de la necesidad de consideraciones fundamentales acerca del valor real de los impresionantes conocimientos adquiridos por las ciencias de la naturaleza, la biología y la cosmología de modo particular; de la necesidad de averiguar hasta que punto este conocimiento expresa la realidad más profunda. Entre las aportaciones de una cosmología totalmente renovada, sabemos hoy que pertenecemos a un planeta de una estrella llamada Sol, similar a cientos de millones de estrellas que forman nuestra galaxia, la Vía Láctea, y semejante a catorce mil de otras galaxias sólo entre las más cercanas, que se agrupan formando cúmulos y otras estructuras. Huelga a este propósito mencionar las recientes aportaciones de la ciencia natural. Entre muchas otras, los procedimientos experimentales de amplificación del DNA; los imprevisibles éxitos de las especies transgénicas, animales y vegetales, como sistemas de producción de materiales humanos; las modernas técnicas de clonación destinadas tanto a la reproducción como a la obtención de materiales celulares especializados con fines terapéuticos; el conocimiento del genoma de diversas especies, vegetales y animales, el hombre incluido; las vacunas-DNA y la acción inhibidora de los polinucleotidos antisentido; y las nuevas posibilidades farmacológicas que han abierto los conocimientos de los mecanismos de la transducción de las señales biológicas celulares. Estas y otras muchas aportaciones 


\section{El Español como Lengua de Comunicación Científica}

científicas han sido la causa de la afirmación de Stewart Brand: "La ciencia es lo único noticiable. Cuando uno ojea un periódico o revista, todos los contenidos de interés humano son el mismo "el-dijo-ella-dijo" de siempre, la política y la economía los mismos lastimosos dramas cíclicos, las modas una patética ilusión de novedad, y hasta la tecnología es previsible si uno sabe algo de ciencia. La naturaleza no cambia demasiado; la ciencia sí, y los cambios se acumulan alterando el mundo de manera irreversiblen. De tal forma son, sin embargo, estos cambios, que el mayor cambio es el ritmo del cambio mismo.

$\mathrm{Al}$ lado de esta colección de formidables creaciones y descubrimientos de la ciencia y de la técnica, y, seguramente, por causa de ellos, ha surgido en los últimos años una singular y directa comunicación social de los científicos basada en la difusión de sus propios planteamientos filosóficos y de gran cultura. Y así, unas cuantas docenas de científicos investigan $\mathrm{y}$, a través de su propia obra, difunden con extraordinaria solvencia las cuestiones más importantes de nuestros días, y conectan directamente con el público, sin intermediarios, y con estilo literario. Entre otros muchos ejemplos, Penrose y La nueva mente del emperador; Gell-Mann y $\mathrm{El}$ quark y el jaguar; Dawkins y El gen egoista y El relojero ciego; El dedo pulgar del panda y La vida maravillosa de Gould; Microcosmos de Margulis; Los mitos de la materia de Davies; Pérez Mercader y ¿Qué sabemos del Universo; y La unidad del conocimiento de Wilson. Y otros menos recientes y más iniciadores del estilo, entre los que sobresalen $\mathrm{El}$ azar y la necesidad de Monod y La estatua interior de Jacob.

No hay lugar a dudas, pues, de que en la creación de esta nueva cultura, y, por tanto, de su comunicación, la ciencia natural está dando grandes pasos para aliviar la amputación inicial y para participar, al menos, en la reconstrucción de su globalidad bajo las formas de creación literaria y, sobre todo, de filosofía de la naturaleza. A su lado, y habida cuenta de que las humanidades no participan de la adquisición de conocimiento positivo al estilo del que suministran las ciencias positivistas; y si, además, los papeles atribuibles a las humanidades de orientación o de compensación de la ciencia resultan ya desmesurados ya exiguos, y muestran en exceso preponderancia o timidez; resulta obligada una llamada a la reflexión sobre la función de las humanidades en el mundo moderno, que no tenga que suponer la señalización territorial de la cultura. Función que, al contrario, deberá concebir una calidad de cultura más extensa que suponga la totalidad de las formas de la dedicación del hombre, con inclusión tanto de las ciencias y la tecnología como de las humanidades y sus partes. Calidad de cultura que implique la comunidad de 
todas las versiones del conocimiento en la expresión de la racionalidad común que ha creado el mundo moderno. Y dentro de esta calidad-como ha señalado recientemente el profesor Jürgen Mittelstrass, de la universidad de Konstanza-, las humanidades ejercerían la reflexión crítica y constructiva sobre la forma cultural del mundo moderno, fundamental ciertamente para la estabilización y desarrollo de las sociedades modernas, cimentadas más y más cada día en el conocimiento científico y el desarrollo técnológico. Reflexión que contribuirá al interés del individuo y de la sociedad, a las ansias espirituales del hombre, a la satisfacción del placer material como motor primario de la actividad humana; y que, de otro lado, deberá abordar los trascendentes problemas que surgen de todo ello, tales como la disposición ética, individual y social, ante el alargamiento de la vida, el crecimiento del ocio, la manipulación de su propia evolución biológica; y, a no dudarlo, ante el determinismo molecular de la salud, la enfermedad e, incluso, de las cualidades del hombre. Para, en resumen, intentar conciliar al hombre con la cultura global. 